1. MBBS, FCPS

Senior Registrar Gyne \& Obs Kharadar General Hospital, Karachi.

2. MBBS, FCPS

Assistant Professor Gyne \& Obs

Bahria University Medical \& Denta College.

3. MBBS, FCPS

Assistant Professor Gyne \& Obs PSAQSHJ Gambat Institute of Medical Sciences.

4. MBBS, FCPS Senior Registrar Gyne \& Obs Holy Family Hospital Karachi.

5. MBBS, FCPS

Assistant Professor Gyne \& Obs Baqai Medical University Karachi.

6. MBBS, MRCOG, FCPS

Consultant Gyne \& Obs Hamdard University Hospital, Karachi.

7. MBBS, MPH Assistant Professor Community Medicine

Bilawal Medical College LUMHS Jamshoro Pakistan.

Correspondence Address:

Dr. Nudrat Zeba

Department of Community Medicine

Bilawal Medical College LUMHS

Jamshoro Pakistan

drnudratzeba@gmail.com

Article received on:

14/12/2018

Accepted for publication:

$15 / 06 / 2019$

\section{FREQUENCY OF MATERNAL AND NEONATAL COMPLICATIONS ASSOCIATED WITH SECOND STAGE CAESAREAN SECTION IN CIVIL HOSPITAL KARACHI, PAKISTAN.}

\begin{abstract}
Sana Mubarak Ali', Shahida Karamat ${ }^{2}$, Asifa Abdul Jabbar Khawaja ${ }^{3}$, Huma Urooj ${ }^{4}$, Farheen Shaikh ${ }^{5}$, Saima Farooq ${ }^{6}$, Nudrat Zeba ${ }^{7}$

ABSTRACT: Normal vaginal delivery is not replaced by caesarean section over the period of last century in spite of being safer in terms of maternal and neonatal morbidity, mortality and even cost. The trend of caesarean section increasing day by day, which is being a huge concern in many parts of the world. Objectives: To assess the frequency of maternal and neonatal morbidity associated with second stage caesarean section. Study Design: Descriptive case series. Study Setting: Gynecology and Obstetrics unit 3, Civil Hospital Karachi. Period: June to November 2015. Material \& Methods: A total of 123 pregnant women undergoing second stage caesarean section were included in this study. Data regarding demographic characteristics and complications during caesarean section were identified and noted. Neonatal outcome records were also collected on predesign pro-forma. Results: Primary postpartum hemorrhage was $14.6 \%$ cases; extension of a transverse uterine incision $7.3 \%$ and need of blood transfusions $17.1 \%$ cases as well as $30.1 \%$ of the women had a hospital stay of three to five days. There were $86.2 \%$ alive babies, $7.3 \%$ still births and $13 \%$ early neonatal deaths. $13 \%$ neonates required admission to the neonatal intensive care unit. Conclusion: Overall, maternal and neonatal morbidities during second stage caesarean sections were not very high.
\end{abstract}

Key words: $\quad$ Caesarean Section, Maternal and Neonatal Morbidity, Second Stage.

Article Citation: Ali SM, Karamat S, Khawaja AAJ, Urooj H, Shaikh F, Farooq S, Zeba N. Frequency of maternal and neonatal complications associated with second stage caesarean section in Civil Hospital Karachi, Pakistan. Professional Med J 2020; 27(3):535-539. DOI: 10.29309/TPMJ/2020.27.3.3429

\section{INTRODUCTION}

Normal vaginal delivery is not replaced by caesarean section over the last century in spite of being safer in terms of maternal and neonatal morbidity, mortality and even cost. The trend of caesarean section increasing day by day, which is being a huge concern in many parts of the world. ${ }^{1}$

In low middle-income countries among all deliveries caesarean section frequency ranges from $20-30 \% .^{2}$

WHO indicated that a caesarean section rate greater than $10 \%$ is not acceptable in any region around the globe. ${ }^{1}$ According to the study which was done in Singapore, rate of second stage caesarean section is $4.4 \% .^{2}$

Past studies revealed that approximately $25 \%$ of caesarean sections are being performed during second stage of labour and are thought to be leading to more complications as compared to first stage of labour. ${ }^{3}$

Caesarean section in a fully dilated patient is a tough task and is usually carried out after failure of the instrumental delivery with the fetal head completely engaged in the pelvis of the patient. There is huge risk of maternal and neonatal morbidity. 4

Major maternal risks are hemorrhage, broad ligament entanglement, damage to the neighboring soft tissues (bladder, bowel and urethra) and laceration of the lower uterine segment. $^{2}$

Studies have shown that after a prolonged second stage of labour there is thinning of lower uterine segment and during the delivery of fetal head the incision may cross over into the angles 
of uterus and vagina. The women are also at risk of hemorrhage due to uterine atony if there is prolonged labour with oxytocin augmentation. ${ }^{5}$

According to a study which was done in Jamshoro, the maternal morbidity with second stage caesarean section was in the form of paralytic ileus $14.5 \%$, PPH $12.5 \%$, wound infection $8.33 \%$ and tear extensions $5.41 \%$. Regarding the perinatal outcome, there were $86.66 \%$ alive babies, $5.8 \%$ still births and $7.5 \%$ early neonatal deaths. $^{6}$

In another study, which demonstrated fetal and maternal morbidities associated with second stage caesarean sectionsshowed that $14.3 \%$ cases had a postpartum hemorrhage with blood loss of greater than or equal to $1000 \mathrm{ml}$ andmore than half of the women have to stay more than four days in hospital.

About $13 \%$ of neonates were admitted in the NICU, the APGAR score of about $5 \%$ of babies was poor showing less than 5 at 1 minute and less than 7 at 5 minutes and slightly less than $25 \%$ of babies have liquor stained with meconium during the process of labour and delivery. ${ }^{4}$

A study by Ojeme DSet al showed that women are 4.6 times more likely to have composite maternal intraoperative complications while undergoing caesarean section with full cervical dilatation, these patients required more blood transfusion compared to first stage caesarean section almost $14 \% .^{5}$

In a study done by Govender et al if was found out that the risk of maternal morbidity is higher in second stage caesarean section, however neonatal complication is more likely to occur in first stage caesarean section. ${ }^{7}$

\section{METHODOLOGY}

A descriptive case study was conducted in gynecology and obstetrics ward Civil Hospital Karachi, Sindh Pakistan from June to November 2015. With frequency of $5.41 \%$ (taken from previous study carried out in Jamshoro, Sindh) ${ }^{6}$, precision level $5 \%$ and confidence interval of
95\% the sample size came out to be 123 through OPEN EPI software, with $4 \%$ margin of error. The sampling technique used was through nonprobability convenient sampling during the study period and structured proforma was administered to their patients to gather the required information. All those womenbetween 15 to 45 years of age having full term (37 to 42 weeks) singleton pregnancy and having parity between 1 to 4 with previous history of normal delivery were included in the study.

Whereas, those women having twin pregnancy, preterm delivery, antepartum hemorrhage or having previous cesarean section were excluded from the study. Informed consent was taken from all the subjects before the collection of data and further confirmation was done on ultrasonography. The data collected was edited on an ongoing basis followed by double data entry in SPSS version 19. After entering the data into SPSS, data cleaning was performed. Frequencies of each variable section were calculated.

\section{RESULTS}

During the study period total of 123 pregnant women undergoing second stage caesarean section were included in this study. The average age and duration of hospital stay of the women was $26.52 \pm 6.12$ years and $4.45 \pm 0.78$ days. Out of 123 cases, $41(33.33 \%)$ had primiparous and $82(66.67 \%)$ had multiparty. Regarding socio economic status of the women, most of the women belonged low and middle class that is around $95 \%$.

Nutrition status was observed with respect to BMI and hemoglobin level, low BMI was observed in $7.3 \%$ case and anemia was in $26 \%$ cases. Maternal outcomes including primary postpartum hemorrhage was recorded in $14.6 \%$ cases; extension of a transverse uterine incision $7.3 \%$ and need of blood transfusions $17.1 \%$ cases as well as $30.1 \%$ of the women had a hospital stay of three to five days. These results are summarized in Table-l. 


\begin{tabular}{|c|c|c|}
\hline Maternal Outcome & Frequency & Percentage \\
\hline $\begin{array}{l}\text { Primary Postpartum } \\
\text { Hemorrhage (PPH) } \\
\text { Yes } \\
\text { No }\end{array}$ & $\begin{array}{c}18 \\
105\end{array}$ & $\begin{array}{l}14.6 \% \\
85.4 \%\end{array}$ \\
\hline $\begin{array}{l}\text { Extension of Transverse } \\
\text { Uterine Incision } \\
\text { Yes } \\
\text { No }\end{array}$ & $\begin{array}{c}09 \\
114\end{array}$ & $\begin{array}{c}7.3 \% \\
92.7 \%\end{array}$ \\
\hline $\begin{array}{l}\text { Need of Blood } \\
\text { Transfusions } \\
\text { Yes } \\
\text { No }\end{array}$ & $\begin{array}{c}21 \\
102\end{array}$ & $\begin{array}{l}17.1 \% \\
82.9 \%\end{array}$ \\
\hline $\begin{array}{l}\text { Duration of Hospital Stay } \\
\leq 3 \text { days } \\
3 \text { to } 5 \text { days }\end{array}$ & $\begin{array}{l}86 \\
37\end{array}$ & $\begin{array}{l}69.9 \% \\
30.1 \%\end{array}$ \\
\hline
\end{tabular}

Regarding the perinatal outcome, there were $86.2 \%$ alive babies, $6.5 \%$ still births and $7.3 \%$ early neonatal deaths. $13 \%$ neonates required admission to the neonatal intensive care unit as presented in Table-Il.

\begin{tabular}{|l|c|c|}
\hline \multicolumn{1}{|c|}{ Neonatal Outcome } & Frequency & Percentage \\
\hline Still Birth & 8 & $6.5 \%$ \\
\hline Early Neonatal Death & 9 & $7.3 \%$ \\
\hline Alive & 106 & $86.2 \%$ \\
\hline NICU Admission & 16 & $13 \%$ \\
\hline \multicolumn{2}{|c|}{ Table-II. Neonatal Outcome. } \\
\hline \multicolumn{2}{|c|}{} \\
\hline
\end{tabular}

\section{DISCUSSION}

Nowadays, the increasing trend of caesarean section is under huge debate throughout the globe. Much discussion is concentrated over the morbidity followed for vaginal birth after caesarean section, type of delivery for breech presentation and also about maternal choice of delivery. ${ }^{8,9}$ Number of women undergo caesarean section without any planning for it, only because of prolonged and difficult second stage of labour after being well set for the normal vaginal delivery. The major issue faced by the obstetricians' face is how to reduce the frequency of maternal and neonatal morbidity when there is option of either to go for caesarean section or difficult vaginal instrumental delivery.
The rise in the rate of caesarean delivery is known to be due to transformation in obstetric practice and characteristics of mothers, such as rising maternal age, increasing weight with or without pregnancy, rate of labour induction due to the use of epidural anesthesia, compatible with risk factors recognized for delivery by caesarean section in initial two stages of labour. These foreseen continuous changes in maternal attributes and practices by obstetricians anticipate rising trends of caesarian section delivery in second stage of labour. ${ }^{10,11,12}$

Recent data from Nova Scotia indicated that there are more chances of maternal morbidity with caesarean section during labour rather than caesarian section without labour. ${ }^{13}$ With cervix fully dilated and head of fetus completely engaged the caesarean section can be technically troublesome and may be associated with the trauma to the adjacent soft tissues and lower segment of the uterus, the chances of infection and hemorrhage are also increased in this scenario. ${ }^{14}$ Facilitation by an assistant pushing up from below have been traditionally used in difficult delivery with impacted head of fetus. ${ }^{14}$ The outcome of the recent randomized trial has confronted this technique, demonstrating that a fetus with completely engaged head can be delivered more securely and rapidly by utilizing the option of reverse breech delivery technique. In this way rather than pushing out, the head of the fetus will be pulled. ${ }^{14}$

The current study intended to further elaborate the effect of delivery in second stage of labour on perinatal and maternal illnesses, revealed not statistically and clinically remarkably increased risk of trauma to the patient during the operative procedure and perinatal asphyxia in caesarean section with cervix fully dilated. A study by Allen et al revealed that women undergoing caesarean section at less than full cervical dilatation have less chance of developing trauma during surgery as well as perinatal asphyxia as compared to women those who underwent caesarean section at full cervical dilatation. In his retrospective study he also revealed that there is 2.6 times more chance of maternal intraoperative complication 
( $P$ >0.001) in women undergoing caesarean section with cervix fully dilated. However, there was no statistically significant association of febrile morbidity, post-partum hemorrhage, hysterectomy, blood transfusion and wound infection. His findings are contrasting to the current study..$^{15}$ Another study by Radha et al in 2009 found out that there is no statistically significant association between caesarean section in second stage of labour and maternal trauma or adverse perinatal outcomes. ${ }^{2}$ These findings are similar to our study.

In our study extension of transverse uterine incision was found in a smaller number of cases while according to Clark et al, slightly less than half of the subjects were found to be at risk of Caesarean hysterectomy and febrile morbidity and also an extension of the uterine incision. ${ }^{16} \mathrm{His}$ findings are contrasting to our study. ${ }^{16}$

To reduce the number of second stage caesarean sections and its related complications it is always essential that the decision regarding the procedure should be taken by the senior obstetrician. This was highlighted by Govender et al in his recent study. The study concluded that the guidance from the senior obstetricians and consultants is very little in decision making regarding second stage caesarean section although maternal mortality and neonatal complications were higher in second stage than first stage caesarean section. ${ }^{7}$

In our study there were $17 \%$ cases required blood transfusions as well as $30 \%$ of the women had a hospital stay of three to five days. The study by Robertson PA et al also revealed similar findings particularly in relation to hospital stay of mothers and blood loss. ${ }^{17}$

Regarding the perinatal outcome, our study shows that there were $86 \%$ alive babies, $7 \%$ still births and $13 \%$ early neonatal deaths. $13 \%$ neonates required admission to the neonatal intensive care unit. This over all low rate of serious neonatal morbidity is consistent with the results of previously done studies. ${ }^{18,19}$ Assessment of neurological and neurodevelopmental outcomes requires long term follow-up. Although only few children are affected from neurodevelopmental problems but its outcomes could be far reaching.

The study design of the current study is the enhancement to the past retrospective studies, as it took into consideration all those subjects who were with arrested second stage of labour and represented almost the full range of actual practices. The researcher might not have been able to recognize the key confounding factors. Therefore, there is a need of complete randomized control trial in order to have gold standard results. First when the mother is in obstructed labour the decision on mode of delivery is dependent on many factors like, risk of attempted vaginal delivery, the consultants' subjectivity on success of mode of delivery and last but not the least mothers' wish. There are truly a very little balanced situations for an obstetrician on mode of delivery. Second, it is thought to be unethical to recruit the study subjects during labour as it could result in obstructed labour due to distress of the mother. Further pregnant women would probably find it difficult to leave the decision to undertake caesarean section in labour to chance. In the first instance we need to undertake a pilot study to assess feasibility and acceptability of such a trial.

\section{CONCLUSION}

Overall, maternal and perinatal morbidities during second stage Caesarean sections were not very high. The rate of complications may have been avoided by improvement of antenatal care, assessment in early labour by experienced obstetricians and timely intervention.

Copyright @ 15 June, 2019.

\section{REFERENCE}

1. Karim F, Ghazi A, Ali T, Aslam R, Afreen U, Farhat R. Trends and determinant of caesarean section. J Surg Pak. 2011; 16(1):22-7.

2. Radha P, Tagore S, Rahman MFA. Maternal and perinatal morbidity after caesarean delivery at full cervical dilatation. Singapore Med J. 2012; 53(10):6558. 
3. Sucak A, Celen S, Akbaba E, Soysal S, Moraloglu O, Danisman N. Comparison of nulliparous undergoing caesarean section in first and second stage of labour; A prospective study in tertiary teaching hospital. BJOG. 2011.

4. Unterscheider J, McMenamin M, Cullinane F. Rising rates of caesarean deliveries at full cervical dilatation: A concerning trend. Eur J Obstet Gynaecol Reprot Biol. 2011; 157-141.

5. Ojeme DS, Sathiyathasan S, Fayyaz M. Caesarean delivery at full cervical dilatation versus caesarean delivery in the first stage of labour: Comparison of maternal and perinatal morbidity. Arch Gynecol Obstet. 2008; 245-9.

6. Baloch S, Khaskheli M, Khushk IA, Sheeba A. Frequency of second stage intervention and its outcome in relation with instrumental vaginal delivery versus caesarean section. JAMC. 2008; 20(1):87-90.

7. Govender V, Panday M, Moodley J. Second stage caesarean section at a tertiary hospital in South Africa. J Maternal Fetal Neonatal Med. 2010; 23(10):1151-5.

8. Wagner M. Choosing caesarean section. Lancet. 2000; 356:1677-80.

9. Hannah ME, Hannah WJ, Hewson SA, Hodnett ED, Saigal S, Willan AR. Planned caesarean section versus planned vaginal birth for breech presentation at term: a randomized multicenter trial. Term Breech Trial Collaborative Group. Lancet. Oct 21 2000; 356(9239):1375-83.

10. Joseph KS, Young DC, Dodds L. Changes in maternal characteristics and obstetric practice and recent increases in primary caesarean delivery. Obstet Gynecol. 2003; 102:791-800.
11. Murphy DJ, Liebling RE, Verity L, Swingler R, Patel R. Early maternal and neonatal morbidity associated with operative delivery in the second stage of labour: A cohort study. Lancet. 2001; 358:1203-7.

12. Sheiner E, Levy A, Feinstein U, Hallak M, Mazor M. Risk factors and outcome of failure to progress during the first stage of labor: A population-based study. Acta Obstet Gynecol Scand. 2002; 81:222 -6.

13. Allen VM, O'Connell CM, Baskett TF. Maternal morbidity associated with cesarean delivery without labor compared with spontaneous onset of labor at term. Obstet Gynecol. 2003; 102:477-82.

14. Fasubaa OB, Ezechi OC, Orji EO. Delivery of the impacted head of the fetus at caesarean section after prolonged obstructed labour: A randomized comparative study of two methods. J Obstet Gynaecol. 2002; 22:375-8.

15. Allen VM, O'Connell CM, Baskett TF. Maternal and Perinatal morbidity of caesarean delivery at full cervical dilatation compared with caesarean delivery in the first stage of labour. BJOG. 2005; 112:986-90.

16. Clark SL, Yeh SY, Phelan JP, Bruce S, Paul RH. Emergency hysterectomy of obstetric hemorrhage. Obstet Gynecol. 1984; 64:376-80.

17. Robertson PA, Laros RK Jr, Zhao RL. Neonatal and maternal outcome in low-pelvic and midpelvic operative deliveries. Am J Obstet Gynecol. 1990; 162:1436-42.

18. Revah A, Ezra Y, Farine D, Ritchie K. Failed trial of vacuum or forceps: Maternal and fetal outcome. Am J Obstet Gynecol. 1997; 176:200-4.

19. Lowe B. Fear of failure: A place for the trial of instrumental delivery. $\mathrm{Br} J$ ObstetGynaecol. 1987; 94:60-6.

\begin{tabular}{|c|c|c|c|}
\hline \multicolumn{4}{|c|}{ AUTHORSHIP AND CONTRIBUTION DECLARATION } \\
\hline Sr. \# & Author(s) Full Name & Contribution to the paper & Author(s) Signature \\
\hline 1 & Sana Mubarak Ali & Data collection. & \\
\hline 2 & Shahida Karamat & Data collection. & \\
\hline 3 & Asifa Abdul Jabbar Khawaja & Data analysis. & \\
\hline 4 & Huma Urooj & Results Formulation. & \\
\hline 5 & Farheen Shaikh & Results Formulation. & \& \\
\hline 6 & Saima Farooq & Results Formulation. & \\
\hline 7 & Nudrat Zeba & Results Formulation. & $N_{400}$ \\
\hline
\end{tabular}

